\title{
Duodenal diverticulitis: a rare cause of abnormal liver function tests
}

A 52-year-old woman presented with a 2-week history of pain in her right upper abdomen radiating to the ipsilateral shoulder, associated with pale colored stools, dark colored urine, and a poor appetite, without febrile episodes. Physical examination revealed right upper quadrant tenderness with a positive Murphy's sign. Initial tests revealed leukocytosis with aspartate transaminase at $245 \mathrm{IU} / \mathrm{L}$ (up to $42 \mathrm{IU} / \mathrm{L}$ ), alanine transaminase $283 \mathrm{IU} / \mathrm{L}$ (up to $40 \mathrm{IU} / \mathrm{L}$ ), alkaline phosphatase $257 \mathrm{IU} / \mathrm{L}$ (up to $92 \mathrm{IU} / \mathrm{L}$ ), total bilirubin $1.5 \mathrm{mg} / \mathrm{dL}$ (up to $1.2 \mathrm{mg} / \mathrm{dL}$ ), and direct bilirubin $0.6 \mathrm{mg} / \mathrm{dL}$ (up to $0.4 \mathrm{mg} / \mathrm{dL}$ ).

A computed tomography (CT) scan with contrast revealed a distended gallbladder with intrahepatic biliary duct (IHBD) dilation and a dilated common bile duct (CBD) $(12 \mathrm{~mm})$. A cystic lesion with an air-fluid level was identified posterior and inferior to the head of pancreas, close to the CBD ( Fig.1). Magnetic resonance cholangiopancreatography confirmed the dilation of the IHBD and CBD, defined the cystic mass as a duodenal diverticulum of less than $4 \mathrm{~cm}$ ( $\bullet$ Fig. 2 ), and confirmed there were no stones in the CBD or gallbladder. On day 2 of admission, the patient developed a fever spike of $39.6^{\circ} \mathrm{C}$ and underwent endoscopic retrograde cholangiopancreatography (ERCP), which revealed a large diverticulum in the second part of the duodenum, filled with pus and debris ( $\bullet$ Fig.3), and with the ampulla of Vater located on the superior lip of the diverticulum ( Fig.4). The ampulla was easily cannulated, and no CBD stones were demonstrated. In the absence of pus extruding from the ampulla, cholangitis was excluded.

The patient was managed with intravenous antibiotics and bowel rest. Resolution of IHBD and CBD dilation was shown on follow-up CT scans, and liver tests had normalized.

The duodenum is the second most common site for gastrointestinal diverticula [1]. Approximately $75 \%$ are located at the second portion, usually remaining asymptomatic [1]. Nevertheless, complications most commonly perforation and hemorrhage - can develop in $5 \%$ of patients, with diverticulitis being a rare entity [2].

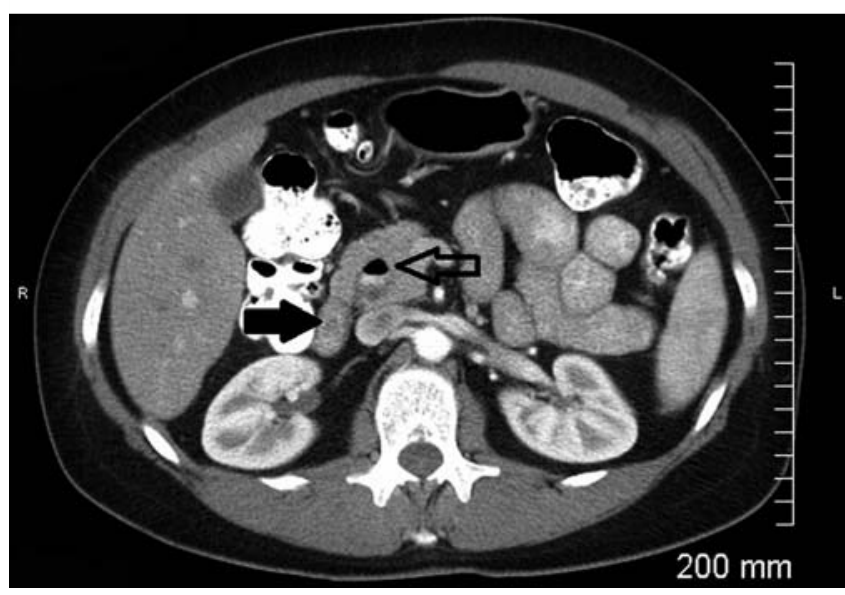

Fig. 1 Computed tomography $(\mathrm{CT})$ scan of the abdomen and pelvis, demonstrating a cystic lesion with an air-fluid level posterior and inferior to the head of the pancreas (outline black arrow). The solid black arrow points to the duodenum.

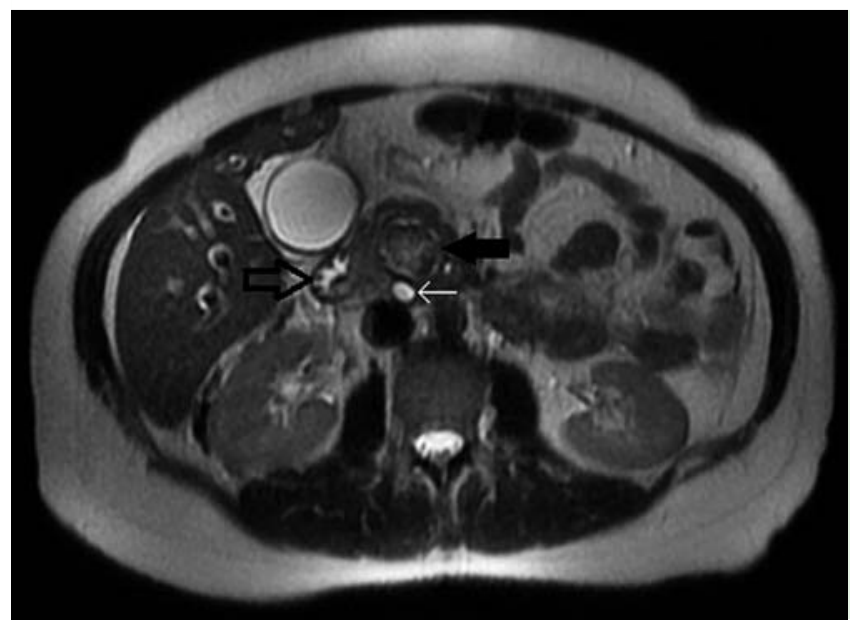

Fig. 2 T2-weighted magnetic resonance cholangiopancreatography image demonstrating a duodenal diverticulum (solid black arrow) arising from the duodenum (outline black arrow), and showing the proximity of the diverticulum to the common bile duct (CBD; white arrow).

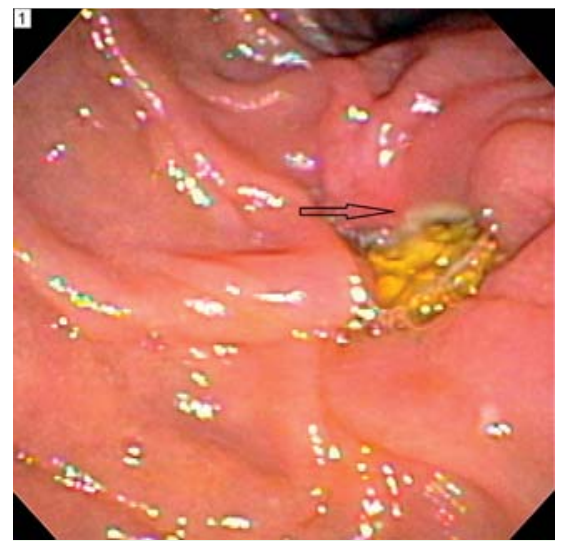

Fig. 3 Diverticulum in the second part of the duodenum, with pus (black arrow) and debris.

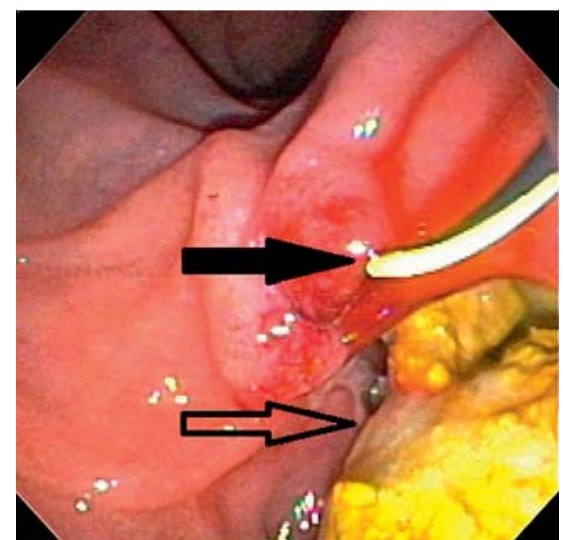

Fig.4 Ampulla of Vater (solid black arrow) located on the superior lip of the diverticulum, with pus in the diverticulum (outline black arrow). 
The signs and symptoms of diverticulitis are non-specific, including abdominal pain, fever, and leukocytosis [2], with CBD obstruction with or without cholangitis being a rare entity [3]. In the absence of cholangitis, conservative management has been described [4]; endoscopic management [3] with sphincterotomy of the ampulla and stenting of the CBD is reserved for cholangitis complicating CBD obstruction secondary to diverticulitis. In conclusion, we describe a rare case of duodenal diverticulitis presenting with CBD obstruction without cholangitis, managed conservatively with intravenousantibiotics.

Endoscopy_UCTN_Code_CCL_1AB_2AZ_3AZ

Competing interests: None

\section{P. Deepak ${ }^{1}$, R. Devi², P. Mohan ${ }^{3}$}

${ }^{1}$ Department of Gastroenterology, NorthShore University HealthSystem,

Evanston, Illinois, USA

2 Department of Internal medicine, University of Illinois at Chicago (St. Francis Hospital), Evanston, Illinois, USA

3 Department of Radiology, University of Illinois at Chicago (St. Francis Hospital), Evanston, Illinois, USA

\section{References}

1 Gore RM, Ghahremani GG, Kirsch MD et al. Diverticulitis of the duodenum: clinical and radiological manifestations of seven cases. Am J Gastroenterol 1991; 86: 981 - 985

2 Pearl MS, Hill MC, Zeman RK. CT findings in duodenal diverticulitis. Am J Roentgenol 2006; 187: W392-395

3 Caselitz M, Manns MP, Meier PN. Endoscopic management of duodenal diverticulitis causing common bile duct obstruction and cholangitis. Endoscopy 2002; 34: 591
4 Luz LP, Eloubeidi MA. Duodenal diverticulitis mimicking cholangitis: endoscopic and EUS appearance. Am J Gastroenterol 2009; 104: $2125-2126$

Bibliography

Dol http://dx.doi.org/

10.1055/s-0031-1291519

Endoscopy 2012; 44: E252-E253

(c) Georg Thieme Verlag KG

Stuttgart · New York

ISSN 0013-726X

Corresponding author

P. Deepak, MD

Department of Gastroenterology

NorthShore University Health System

1001 University Place

Evanston

Illinois 60201

USA

Fax: +1-847-570-2073

deepak.parakkal@gmail.com 